\title{
A Novel ZVS Full-Bridge Converter
}

\author{
Nasir \\ Faculty of Science and Technology \\ Bournemouth University, UK \\ Bournemouth, UK \\ nasir@bournemouth.ac.uk
}

\author{
Jon Cobb \\ Faculty of Science and Technology \\ Bournemouth University, UK \\ Bournemouth, UK \\ jcobb@bournemouth.ac.uk
}

\begin{abstract}
Conventional soft switching techniques are promising for improvement of efficiency in full bridge converters. However, efficiency of converters with employing such techniques is restricted due to narrow range of zero voltage switching (ZVS). In such situation, several methods have been proposed in the literature to cope with wide range of ZVS from no load to maximum load. The extra circuitry added to achieve a wide range of ZVS generates more conduction losses in a converter and increase cost of converter. In this paper, a novel ZVS full bridge converter is proposed to eliminate limitations of narrow range $\mathrm{ZVS}$, improved efficiency and reduced cost. The circuit diagram, operation principle of proposed converter is explained and analyzed theoretically in detail. In addition, the proposed converter is built and experimental results are provided to verify the novel ZVS full bridge converter.
\end{abstract}

Keywords- Zerovoltage switching; full-bridge Converter; efficiency; auxiliary circuit

\section{INTRODUCTION}

Full-bridge converters are commonly used for medium-tohigh power applications due to its simple circuit configuration based on hard and soft switching techniques. Hard switching converters are normally turned on and off switches diagonally at same time. Due to overlap between voltage and current in switches causes losses and reduced efficiency of converter. To improve efficiency of converter, soft switching techniques are normally used. The soft-switching technique can be classified into two types such as ZVS (zero voltage switching) and zerovoltage and zero current switching (ZVZCS) [1]. ZVS is most popular technique due to fixed switching frequency and simplicity. In conventional ZVS method, the switches are turned on when voltage across these are nearly equal to zero. To achieve ZVS, the parasitic capacitors of the switches and leakage inductance of transformer are normally utilized to meet the condition of soft switching. This technique improved efficiency of converter and minimizing EMI noise [2]. While on the other hand, there are some limitations of this technique such as narrow range of load handling capability to achieve zero voltage switching. In light load condition, they lose their ability to achieve zero voltage switching due to less energy stored in leakage inductance.

A number of research papers have been published in literature to improve the range of ZVS operation for converter [3-6]. The range of ZVS can be extended by increasing stored energy of inductance using high leakage inductance of transformer or adding series inductance. The effective duty cycle is comprised due to increasing inductance of transformer. The loss of effective duty cycle can be minimized by using saturable inductor in series to achieve ZVS [7]. These methods of increasing the inductance for stored energy can significantly increases current through switches and conduction losses [8]. A full range of ZVS can be achieved by help of passive auxiliary pole circuit that results in fixed circulating current and higher conduction losses. In a nutshell, conduction losses are higher in these types of ZVS techniques of increasing inductance of transformer through different ways such as series inductance, saturable inductor and passive auxiliary pole circuit.

In this paper, a novel technique is proposed to extend the range of ZVS over entire range of load. Moreover, the proposed technique not only increases the range of ZVS but also improves efficiency of full-bridge converter. The experimental results obtained from proposed converter are also presented in paper to confirm our idea.

\section{OPERATION PRINCIPLE OF NOVEL ZVS FULL-BRIDGE CONVERTER}

The circuit diagram of proposed ZVS full-bridge converter is shown in fig 1. In proposed circuit, there are four main switches Q1 Q2 Q3 Q4 (also the parasitic capacitances and body diodes are including as well), $\mathrm{Np} / 2$ and $\mathrm{Np} / 2$ are primary windings of equal turns, Ns1_A, Ns2_A, Ns1_B and Ns2_B are secondary windings, D1-D8 are output rectifier diode, $\bar{L} 1-$ L4 are output filter inductor, C5-C8 are output filter capacitors. Laux is an auxiliary inductor, Caux1 and Caux2 are voltage divider capacitors. The passive energy storage circuit consists of Laux, Caux1 and Caux2.

The converter has several operating cycles to perform ZVS over entire range of cycle. In fig 2-9, the related equivalent circuits under different operating cycles are shown.

For analysis of circuit, several assumptions are made to simplify the analysis such as 1) Ideal components are considered. 2) Inductor of output filter is large enough that it can be considered as a constant current source. 3) Caux 1 and Caux2 can act as a constant voltage source, (Vcaux $1=$ Vcaux2=Vin/2). Whereas Vin=Vbus used in schematic. 


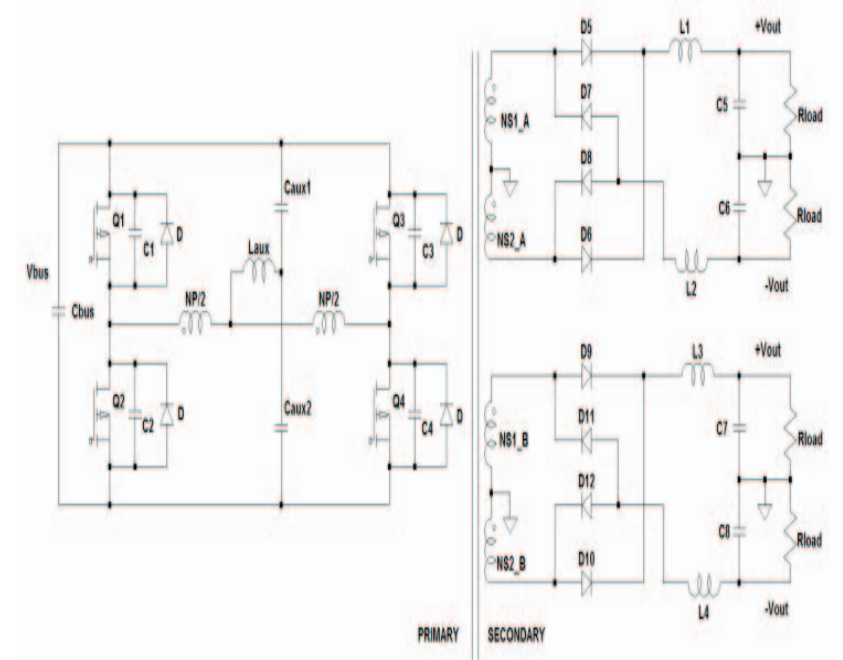

Fig. 1. Schematic of novel proposed ZVS full-bridge Converter

\section{A. Mode 1}

Before time $\mathrm{t} 0$, the power is transferred from input source Vin to the load. The MOSFET Q1 and Q4 are conducting to build the primary voltage across transformer. On the secondary side, the D5, D8, D9 and D12 are conducting to deliver the power to load. The voltage across auxiliary winding is equal to zero VLaux $=0$. Therefore, the current in auxiliary inductor freewheels and remains unchanged.

\section{B. Mode 2}

At to, Q4 is turned OFF and Q1 still turn ON. The auxiliary circuit is providing current to charge up capacitor $\mathrm{C} 4$ and discharge up capacitor $\mathrm{C} 3$. On the secondary side, the diodes become reverse bias and are not conducting. Moreover, the rising voltage across $\mathrm{C} 4$ due to current providing by auxiliary circuit builds up to voltage equal to VIN. At the end of this mode, the voltage across $\mathrm{C} 4$ charges up to input voltage VIN and the capacitor C3 discharges completely.

\section{Mode 3}

This mode starts when C4 charges up to VIN and C3 completely discharges to zero voltage. Also Q1 remains turn $\mathrm{ON}$ in this mode and MOSFET Q3 turns ON at zero voltage across it. Therefore, the free wheel mode builds the constant voltage of VIN across primary windings of transformer and the auxiliary inductor is charging due to voltage across it. Moreover, the secondary diodes clamp the secondary voltage to output voltage.

\section{Mode 4}

At MOSFET Q3 still conducts in this mode as shown in fig 5. However, MOSFET Q1 turns OFF in this mode. The capacitor $\mathrm{C} 2$ is discharging from VIN and $\mathrm{C} 1$ is charging up to VIN. The auxiliary inductor draws a current during this mode which provides energy for discharging $\mathrm{C} 2$ and charging $\mathrm{C} 1$.
The capacitor $\mathrm{C} 1$ charges up and $\mathrm{C} 2$ discharges fully at the end of this mode.

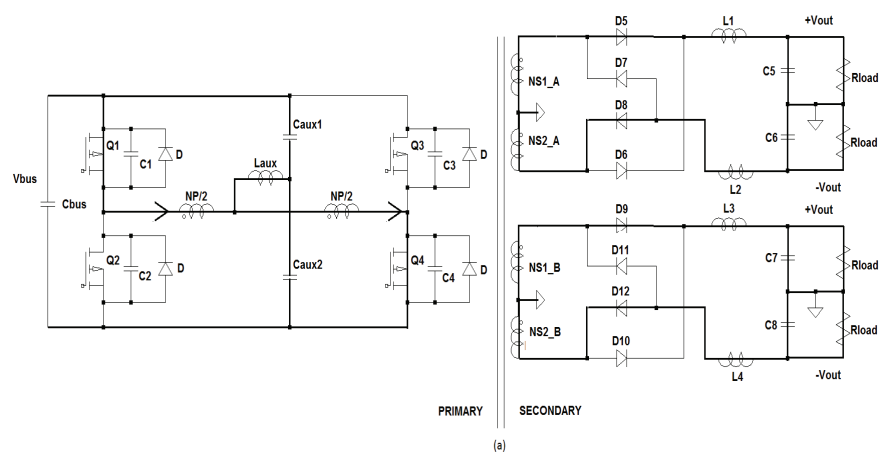

Fig. 2. Active circuit of ZVS full-bridge Converter (mode 1)

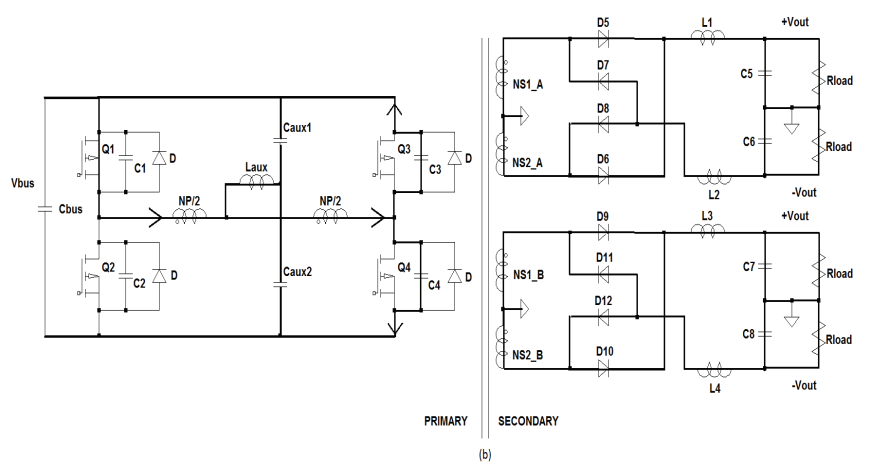

Fig. 3. Active circuit of ZVS full-bridge Converter (mode 2)

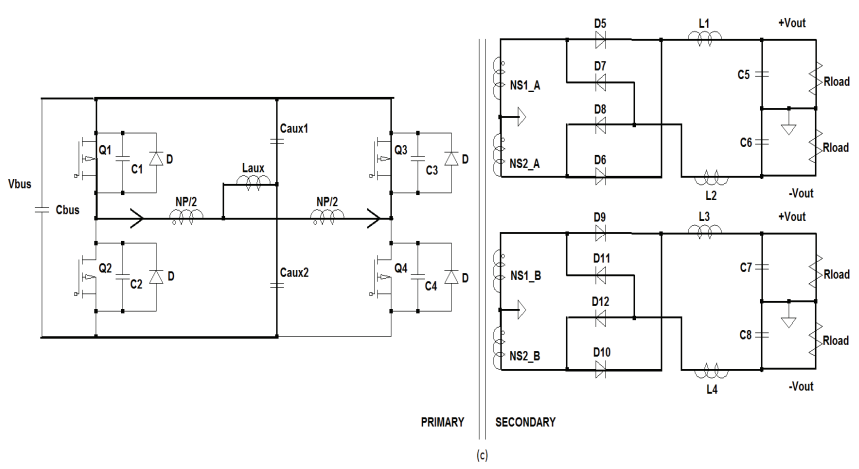

Fig. 4. Active circuit of ZVS full-bridge Converter (mode 3)

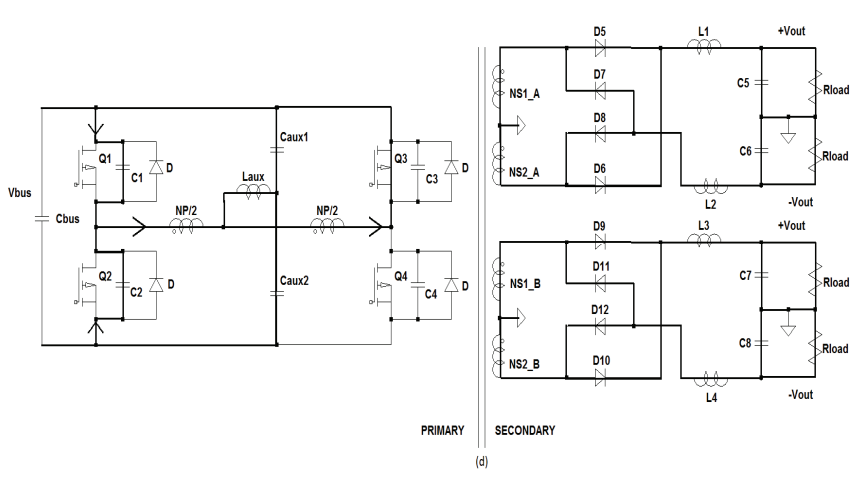

Fig. 5. Active circuit of ZVS full-bridge Converter (mode 4) 


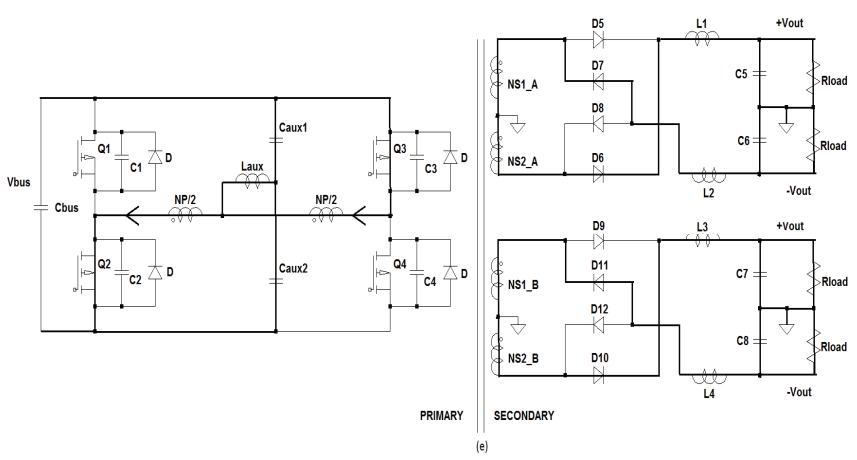

Fig. 6. Active circuit of ZVS full-bridge Converter (mode 5)

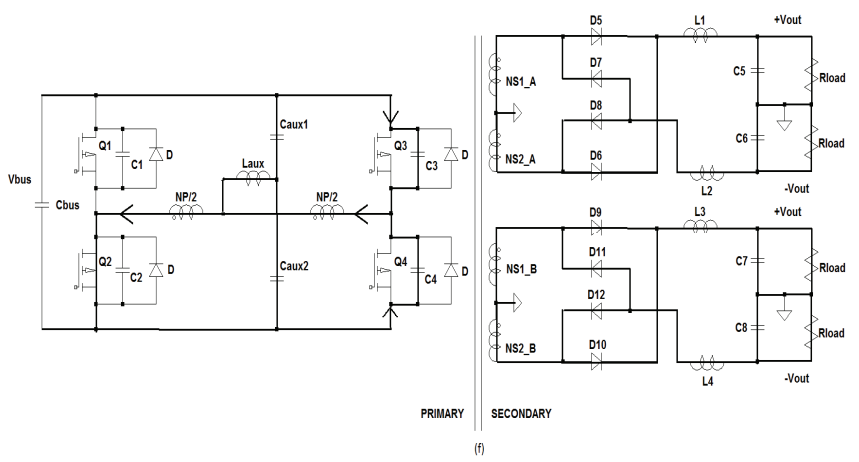

Fig. 7. Active circuit of ZVS full-bridge Converter (mode 6)

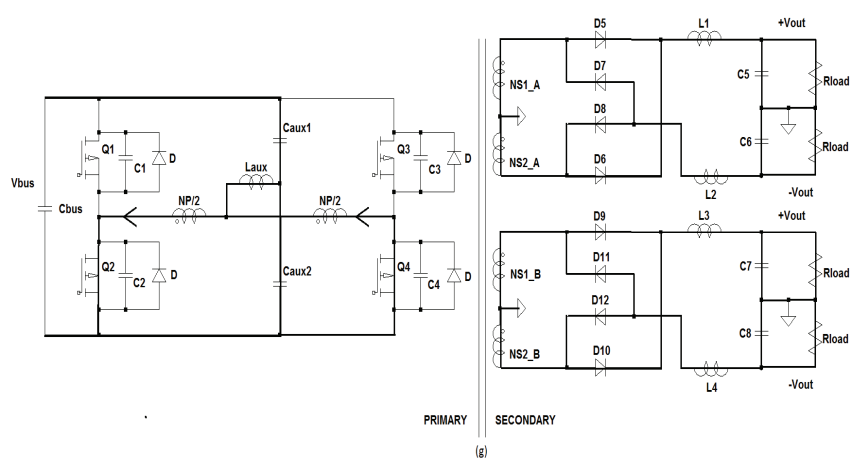

Fig. 8. Active circuit of ZVS full-bridge Converter (mode 7)

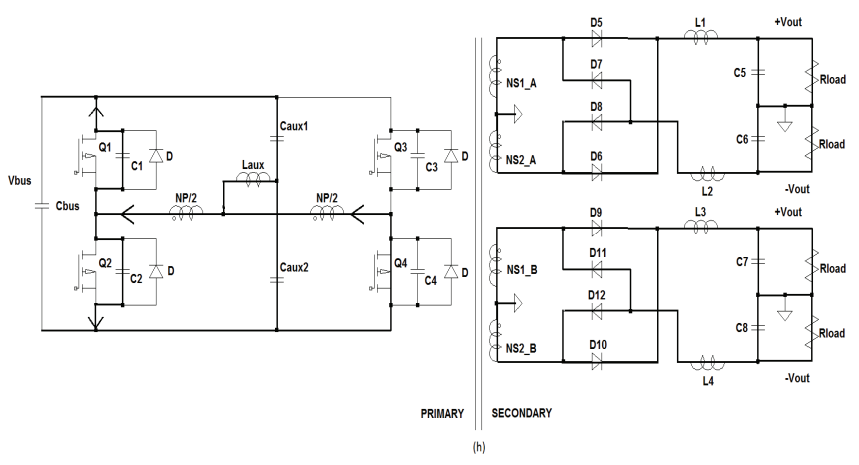

Fig. 9. Active circuit of ZVS full-bridge Converter (mode 8)

\section{E. Mode 5}

In this mode, Q3 still conducts and Q2 turns ON at zero voltage across it. The primary current starts to flow in opposite direction to previous power transfer mode. The power is transferred from primary to secondary side load through Q3 and Q2. The output diodes D6, D7, D10 and D11 start conducts to deliver power to the load.

\section{F. Mode 6}

In this mode, Q3 is turned OFF and Q2 still turn ON. The capacitor $\mathrm{C} 3$ is charging to VIN and capacitor $\mathrm{C} 4$ is discharging from VIN. The auxiliary circuit is drawing current to discharge $\mathrm{C} 4$ and charge up $\mathrm{C} 3$. On the secondary side, the diodes become reverse bias and are not conducting. Moreover, the voltage across $\mathrm{C} 4$ drops to zero due to current drawn by auxiliary circuit and $\mathrm{C} 3$ voltage builds up to VIN. At the end of this mode, the voltage across $\mathrm{C} 3$ charges up to input voltage VIN and the capacitor C4 discharges completely.

\section{G. Mode 7}

This mode starts when $\mathrm{C} 4$ discharges up to zero voltage and $\mathrm{C} 3$ charges up to VIN voltage. Also Q2 remains turn $\mathrm{ON}$ in this mode and MOSFET Q4 turns ON at zero voltage across it. Therefore, the free wheel mode builds the zero voltage across primary windings of transformer and the auxiliary inductor (VLaux) has a voltage across it. The current in auxiliary winding flows in opposite direction. Moreover, the secondary diodes clamp the secondary voltage to output voltage.

\section{H. Mode 8}

MOSFET Q4 still conducts in this mode as shown in fig 9. However, MOSFET Q2 turns OFF in this mode. The capacitor $\mathrm{C} 1$ is discharging from VIN and $\mathrm{C} 2$ is charging up to VIN. The auxiliary inductor provides energy for discharging $\mathrm{C} 1$ and charging $\mathrm{C} 2$ in this mode. The capacitor $\mathrm{C} 1$ discharges and $\mathrm{C} 2$ charges fully at the end of this mode.

\section{EXPERIMENTAL RESULTS AND DISCUSSION}

In order to validate the theory of novel ZVS technique, ZVS full-bridge converter has been investigated by performing experimental tests on proposed technique. The switching frequency of full-bridge converter was $110 \mathrm{KHz}$ with these input and output specification.

TABLE I. SPECIFICATION OF ZVS FULL-BRIDGE CONVERTER

\begin{tabular}{|l|l|c|}
\hline \multirow{2}{*}{} & \multicolumn{2}{|c|}{ ZVS Full-Bridge Converter } \\
\cline { 2 - 3 } & \multicolumn{1}{|c|}{ Specification } & Value \\
\hline 1. & Input Voltage & $230 \mathrm{~V}$ \\
\hline 2. & Input frequency & $50 \mathrm{~Hz}$ \\
\hline 3. & Output Voltage & $\begin{array}{c}+-48 \mathrm{~V} \\
+/-48 \mathrm{~V}\end{array}$ \\
\hline 4. & Output Current & $6 \mathrm{~A}$ \\
\hline 5. & Output Power & $1152 \mathrm{~W}$ \\
\hline
\end{tabular}




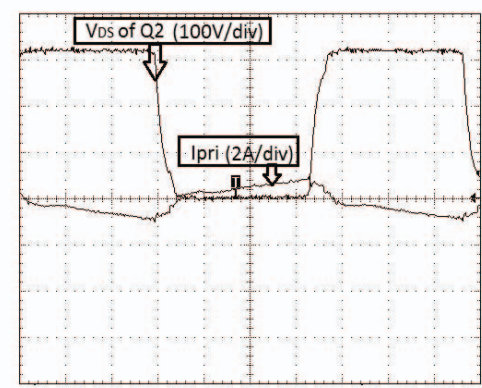

Fig. 10. ZVS waveforms of novel proposed Converter (no load)

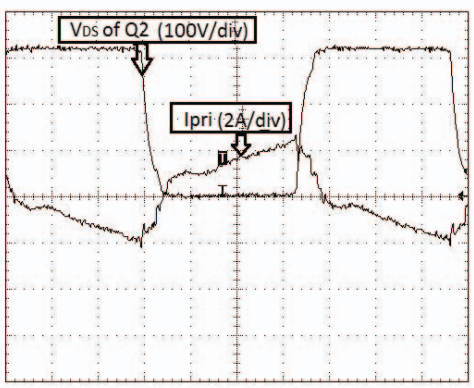

Fig. 11. ZVS waveforms of novel proposed Converter (50\% load)

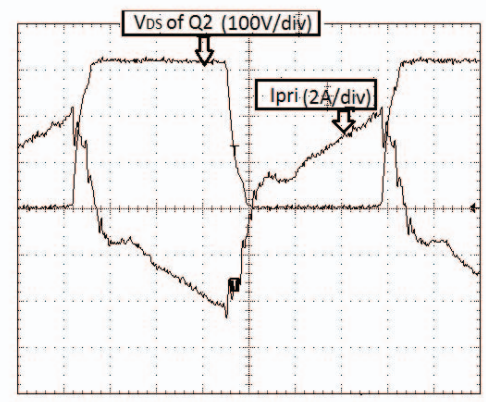

Fig. 12. ZVS waveforms of novel proposed Converter (100\% load)

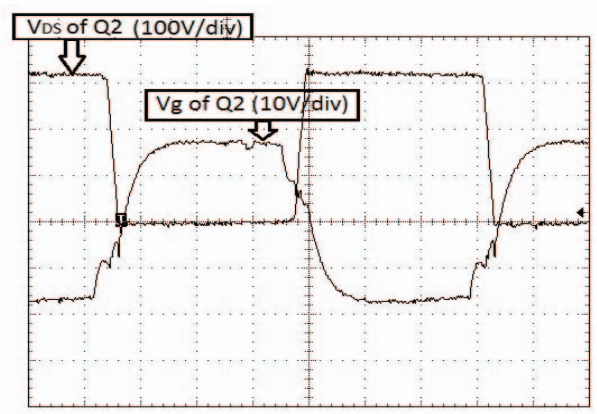

Fig. 13. ZVS waveforms of novel proposed Converter (across MOSFET Q2)

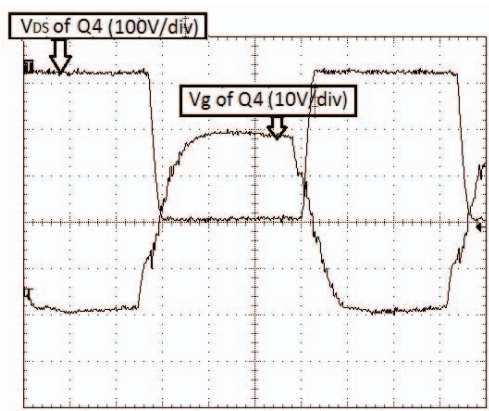

Fig. 14. ZVS waveforms of novel proposed Converter (across MOSFET Q4)

The measurement data for proposed ZVS full-bridge converter are shown in above figures. It is evident from the results that the range of ZVS was extended over entire range of load with proposed ZVS technique. Moreover, the leading and lagging leg MOSFETs can be turn $\mathrm{ON}$ at zero voltage even at no load.

\section{CONCLUSION}

In this paper, a novel ZVS full-bridge converter was proposed to improve the range of zero voltage switching over the entire range of load. Moreover, experimental results prove that ZVS can be achieved for both legs switching devices (leading and lagging MOSFET). It is also evident from proposed circuit that it is a simple and cost effective solution. It also improves the overall efficiency of converter over entire range of load.

\section{REFERENCES}

[1] X. Ruan and Y. Yan, "Soft-switching techniques for PWM full bridge converters,” IEEE PESC, 2000, pp. 634-639.

[2] Z. Chen, B. Ji, F. Ji, and L. Shi, "Analysis and design considerations of an improved ZVS full-bridge DC-DC converter," in Proc. IEEE Appl. Power Electron. Conf., Feb. 21-25, 2010, pp. 1471-1476.

[3] F. Bakan, N. Altintas, and I. Aksoy, "An improved PSFB PWM DC-DC converter for high power and frequency applications," IEEE Trans. Power Electron., vol. 28, no. 1, pp. 64-74, Jan. 2013

[4] I. Lee and G. Moon, "Soft-switching DC-DC converter with a full ZVS range and reduced output filter for high-voltage applications," IEEE Trans. Power Electron., vol. 28, no. 1, pp. 112-122, Jan. 2013.

[5] I.-H. Cho, K.-M. Cho, J.-W. Kim, and G.-W. Moon, "A new phaseshifted full-bridge converter with maximum duty operation for server power system," in Proc. IEEE 8th Int. Conf. Power Electron. ECCE Asia, May 30-Jun. 3, 2011, pp. 1278-1285.

[6] M. Cacciato and A. Consoli, "New regenerative active snubber circuit for ZVS phase shift full bridge converter," in Proc. IEEE Appl. Power Electron. Conf., Mar. 6-11, 2011, pp. 1507-1511.

[7] G. Hua, F. C. Lee, and M. M. Jovanovic, "An improved full-bridge zerovoltage-switched pwm converter using a saturable inductor," IEEE PESC, 1991, pp. 189-194.

[8] R. Ayyanar and N. Mohan, "Novel soft-switching dc/dc converter with full ZVS-range and reduced filter requirement-Part I: regulated output applications," IEEE Trans. on Power Electron., vol. 16, no. 3, pp. 184192, 2001. 